\title{
Eye Position Encoding in Three-Dimensional Space: Integration of Version and Vergence Signals in the Medial Posterior Parietal Cortex
}

\author{
Rossella Breveglieri, ${ }^{1 \star}$ Kostas Hadjidimitrakis, ${ }^{1 \star}$ Annalisa Bosco, ${ }^{1}$ Silvio P. Sabatini, ${ }^{2}$ Claudio Galletti, ${ }^{1}$ \\ and Patrizia Fattori ${ }^{1}$ \\ ${ }^{1}$ Department of Human and General Physiology, University of Bologna, 40126 Bologna, Italy, and ${ }^{2}$ Department of Biophysical and Electronic Engineering, \\ University of Genova, 16145 Genova, Italy
}

\begin{abstract}
Eye position signals are pivotal in the visuomotor transformations performed by the posterior parietal cortex (PPC), but to date there are few studies addressing the influence of vergence angle upon single PPC neurons. In the present study, we investigated the influence on single neurons of the medial PPC area V6A of vergence and version signals. Single-unit activity was recorded from V6A in two Macaca fascicularis fixating real targets in darkness. The fixation targets were placed at eye level and at different vergence and version angles within the peripersonal space. Few neurons were modulated by version or vergence only, while the majority of cells were affected by both signals. We advance here the hypothesis that gaze-modulated V6A cells are able to encode gazed positions in the three-dimensional space. In single cells, version and vergence influenced the discharge with variable time course. In several cases, the two gaze variables influence neural discharges during only a part of the fixation time, but, more often, their influence persisted through large parts of it. Cells discharging for the first 400-500 ms of fixation could signal the arrival of gaze (and/or of spotlight of attention) in a new position in the peripersonal space. Cells showing a more sustained activity during the fixation period could better signal the location in space of the gazed objects. Both signals are critical for the control of upcoming or ongoing arm movements, such as those needed to reach and grasp objects located in the peripersonal space.
\end{abstract}

\section{Introduction}

In everyday life, primates are able to direct eyes and arms toward targets located at different positions. These visually guided actions require the precise localization of targets in threedimensional (3D) space. The medial part of posterior parietal cortex (PPC) is crucial to encode the space and to the control of the visually guided movements (Milner and Goodale, 1995; Galletti et al., 2003; Andersen and Cui, 2009; Kravitz et al., 2011). In humans, lesions of medial PPC severely impair normal visuospatial processing and cause an inability to appreciate the spatial relationships of objects with respect to their own body (Perenin and Vighetto, 1988; Karnath and Perenin, 2005). In many cases, the deficit is more severe in the depth dimension (Baylis and Baylis, 2001; Danckert et al., 2009) and patients are less able, or

\footnotetext{
Received Aug. 5, 2011; revised Oct. 17, 2011; accepted Nov. 7, 2011.

Author contributions:S.P.S., C.G., and P.F. designed research; R.B., K.H., and A.B. performed research; R.B., K.H., and P.F. analyzed data; R.B., K.H., S.P.S., C.G., and P.F. wrote the paper.

This work was supported by European Union Grant FP7-IST-217077-EYESHOTS, by Ministero dell'Università e della Ricerca (Italy), and by Fondazione del Monte di Bologna e Ravenna (Italy). We thank L. Sabattini and R. Mambelli for the technical assistance, N. Marzocchi and G. Placenti for setting up the experimental apparatus, F. Bertozzi for helping in recordings, G. Dal Bo' and A. Canessa for helping in data analysis, and M. Gamberini and L. Passarelli for the anatomical reconstructions.

The authors declare no competing financial interests.

*R.B. and K.H. contributed equally to this work.

Correspondence should be addressed to Prof. Patrizia Fattori, Dipartimento di Fisiologia Umana e Generale, Università di Bologna, Piazza di Porta San Donato, 2, 40126 Bologna, Italy. E-mail: patrizia.fattori@unibo.it.

DOI:10.1523/JNEUROSCI.4028-11.2012

Copyright $\odot 2012$ the authors $\quad 0270-6474 / 12 / 320159-11 \$ 15.00 / 0$
}

totally impaired, in localizing visual targets in depth (Holmes and Horrax, 1919).

The localization in space of foveated targets requires information about the direction of gaze (version) and the depth of fixation (vergence). Several neurophysiological studies have shown that the activity of neurons in many PPC areas is modulated by gaze direction (Sakata et al., 1980; Mountcastle, 1981; Andersen and Mountcastle, 1983; Andersen et al., 1990; Galletti et al., 1995; Squatrito and Maioli, 1996; Bremmer et al., 1997, 2001; Nakamura et al., 1999), but few have demonstrated that single PPC neurons are modulated by vergence (Sakata et al., 1980; Genovesio and Ferraina, 2004; Genovesio et al., 2007; Bhattacharyya et al., 2009). The encoding of both direction of gaze and depth of fixation in single PPC neurons has been to date reported only in area 7a (Sakata et al., 1980).

The present work was designed to test whether eye version and vergence modulate neuronal activity in V6A, a cortical area located in the medial part of monkey PPC (Galletti et al., 1996, 1999a). V6A is strongly connected with PPC areas that encode eye movements and fixations in depth, like the lateral intraparietal area (LIP) and area 7a (Gamberini et al., 2009; Passarelli et al., 2011). It also contains neurons modulated by arm-reaching movements in 3D space (Fattori et al., 2001, 2005; Marzocchi et al., 2008; Bosco et al., 2010), and by gaze position in a frontoparallel plane (Galletti et al., 1995; Nakamura et al., 1999).

Recently, we reported that V6A cells respond preferentially when the gaze is directed to the lower, near space, where the 
hands usually act (Hadjidimitrakis et al., 2011). This finding prompted us to check whether V6A cells are modulated by version and vergence also when fixation points are all located at eye level, thereby excluding any possible effect of the downward looking. We found that the majority of neurons in these experimental conditions were jointly affected by version and vergence signals. We suggest that this eye position information serves to build up a $3 \mathrm{D}$ representation of spatial locations that can be reached out by hands.

Preliminary results have been previously presented in abstract form (Breveglieri et al., 2011).

\section{Materials and Methods}

Two male macaque monkeys (Macaca fascicularis) weighing 4.4 and $6 \mathrm{~kg}$ were studied. Experiments were approved by the Bioethical Committee of the University of Bologna and were performed in accordance with national laws on care and use of laboratory animals, with the European Communities Council Directive of 24 November 1986 (86/609/EEC), and with the Directive of 22 September 2010 (2010/63/EU).

\section{General procedures}

In each monkey, a head restraint system and a recording cylinder were surgically implanted in asepsis under general anesthesia (sodium thiopenthal, $8 \mathrm{mg} \cdot \mathrm{kg}^{-1} \cdot \mathrm{h}^{-1}$, i.v.) following the procedures reported by Galletti et al. (1995). Adequate measures were taken to minimize pain or discomfort. A full program of postoperative analgesia (ketorolac trometazyn, $1 \mathrm{mg} / \mathrm{kg}$, i.m., immediately after surgery, and $1.6 \mathrm{mg} / \mathrm{kg}$, i.m., on the following days) and antibiotic care [Ritardomicina (benzatinic benzylpenicillin plus dihydrostreptomycin plus streptomycin), 1-1.5 $\mathrm{ml} / 10 \mathrm{~kg}$ every $5-6 \mathrm{~d}$ ] followed the surgery.

Single-cell activity was extracellularly recorded from the medial PPC area V6A (Galletti et al., 1996, 1999a). We performed multiple electrode penetrations using a five-channel multielectrode recording system (Mini Matrix; Thomas Recording). Electrodes were quartz-platinum/tungsten fibers with an impedance of $0.5-2 \mathrm{M} \Omega$ at $1 \mathrm{kHz}$ (Thomas Recording). The electrode signals were amplified (gain, 10,000) and filtered (bandpass between 0.5 and $5 \mathrm{kHz}$ ). Action potentials in each channel were isolated with a waveform discriminator (Multi Spike Detector; Alpha Omega Engineering). Spikes were sampled at $100 \mathrm{kHz}$. Signals from both eyes were recorded simultaneously with an infrared oculometer (ISCAN) at a sampling rate of $100 \mathrm{~Hz}$.

\section{Fixation task}

Each monkey sat in a primate chair with the head restrained and faced a horizontal panel located at eye level (Fig. $1 \mathrm{~A}$, left). Nine light-emitting diodes (LEDs) mounted on the panel at different distances from the eyes were used as fixation targets. As shown in the right part of Figure $1 \mathrm{~A}$, the target LEDs were arranged on three isovergence circles corresponding to 18,13 , and $8^{\circ}$ of vergence angle, and along three isoversion rows, one central, along the sagittal midline $\left(0^{\circ}\right)$, and two lateral, at -15 and $+15^{\circ}$ of version angle. Considering the different interocular distances between the two animals ( $3.0 \mathrm{~cm}$ in monkey $\mathrm{A}$ and $3.3 \mathrm{~cm}$ in monkey $\mathrm{B}$ ), as we wanted to use equal vergence angles in the two animals, we placed the first frontal row at a distance of $10 \mathrm{~cm}$ in monkey A and $12 \mathrm{~cm}$ in monkey $B$. The range of vergence angles was chosen to be within the peripersonal space. In fact, when free to touch the LEDs, the monkeys were able to reach all the LEDs of the panel.

The monkeys were trained to fixate in darkness one of the LEDs for a variable time. The time sequence of the task is shown in Figure $1 \mathrm{~B}$. A trial began when the monkey pressed a button [home button (HB)] next to its chest (HB press) while being free to look everywhere. After $1 \mathrm{~s}$, one of the LEDs turned on (LED on). The animal had up to $600 \mathrm{~ms}$ to make an eye movement to fixate the LED; otherwise, the trial was automatically aborted. After either 1 or $1.5 \mathrm{~s}$ from the start of fixation, the LED color changed from green to red and this signaled the end of the task (LED change). The monkey had to release the button to receive reward (HB release).

The monkey's arm ipsilateral with respect to the recording hemisphere was restrained, so the animal pressed and released the button with the

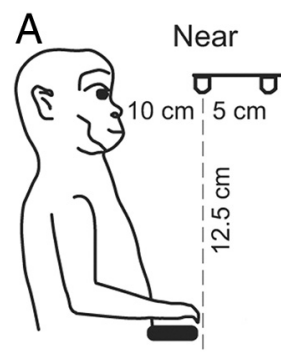

\section{Far}

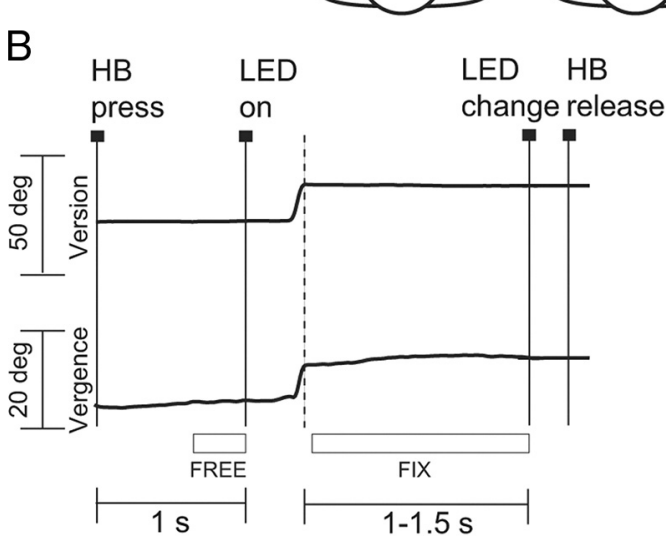

Figure 1. Experimental setup and task sequence. $\boldsymbol{A}$, Scheme of the setup used for the fixation-in-depth task in one monkey. Exact distances are indicated in the lateral view (left) and top views (right). The monkey was fixating in darkness one of the nine LEDs embedded in a panel located at eye level. $\boldsymbol{B}$, Time course of the task. A typical example of the version (top) and vergence (bottom) traces during a single trial is shown. Long vertical continuous lines indicate the occurrence of task and behavioral markers. From left to right markers show the following: trial start (home button, HB press), target appearance (LED light on green, LED on), LED change (green to red change of the LED), and trial end (home button, HB release). The long vertica dashed line indicates the end of the saccade, as detected in the off-line analysis. The squares under eye traces indicate the approximate duration of epochs FREE and FIX (see Materials and Methods).

contralateral hand. Fixation LEDs were chosen trial by trial in random order. During fixation, eye position was controlled by an electronic window $\left(4 \times 4^{\circ}\right)$ centered on each LED. Stimulus presentation and animal's behavior, including eye position signals, were monitored in real time using custom software written in Labview (National Instruments), as described previously (Kutz et al., 2005).

Before each recording session, a specific task allowed us to calibrate the signals from each eye separately. In this task, the monkey fixated in sequence 10 LEDs that were mounted on a fronto-parallel panel at a distance of $15 \mathrm{~cm}$ from the eyes. Five LEDs were tested for each eye. One was placed centrally, aligned with the primary position of the eye, and four peripherally, angled $\pm 15^{\circ}$ along horizontal and vertical axes. From the two individually calibrated eye position signals, we derived the average of the two directions of view, with respect to the primary positions (i.e., the version angle) and their difference (i.e., the vergence angle).

\section{Data analysis}

Fixation period. The mean discharge rate during fixation period was quantified in "FIX" epoch, from $50 \mathrm{~ms}$ after the end of the saccade performed to catch the LED until the LED change indicating to release the button ( 1 or $1.5 \mathrm{~s}$ after saccade offset, according to trial duration). The offset of a saccade, assessed trial by trial, was defined as the time point at which the velocity dropped below $15 \%$ of the peak velocity.

To assess whether a cell was excited or inhibited by fixation, we compared, separately for each spatial location of fixation LED, the activity during FIX with a condition in which the monkey was free to look everywhere (epoch FREE: the last $300 \mathrm{~ms}$ before LED onset; Student's $t$ test, $p<0.05)$. 


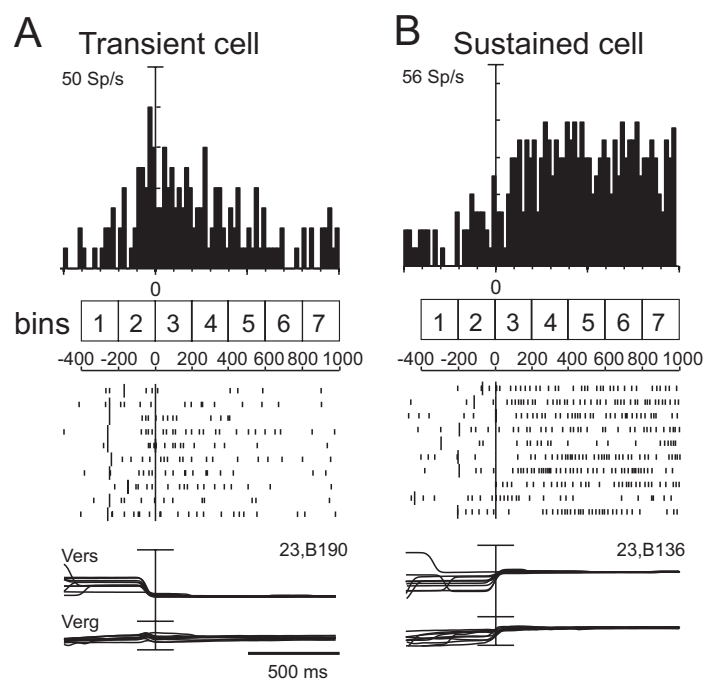

Figure 2. Two typical V6A neurons with different time courses of modulation during the fixation task. From top to bottom in each panel are shown the following: perievent time histograms, raster displays of impulse activity, and recordings of version (Vers) and vergence (Verg) signals. The numbered squares and timescale under histograms indicate the duration and time location of the bins ( $200 \mathrm{~ms}$ each) used for analysis (see Materials and Methods). The short vertical ticks in raster displays are spikes. The long vertical ticks among spikes indicate the occurrence of behavioral events: from left to right, LED onset and saccade offset. Neural activity and eye traces are aligned with the saccade offset. Vertical axis scaling on histogram: $\boldsymbol{A}, 50$ spikes/s; $\boldsymbol{B}, 56$ spikes/s (10 spikes/s per division); bin size, $20 \mathrm{~ms}$; calibration for version and vergence traces, 100 and $20^{\circ}$, respectively.

To assess the relative effects of vergence and/or version and their interaction on the discharge of the cell during FIX, we performed a two-way ANOVA with vergence as factor 1 (three levels: near, intermediate, far) and version as factor 2 (three levels: ipsilateral, central, contralateral) $(p<0.05)$. Neurons with mean firing rate $<5$ spikes/s were excluded from the analysis (Baumann et al., 2009). In the cells with a significant excitatory effect, we calculated the response latency for each LED position. The response latency of the cell was defined as the earliest of the latencies we measured at different positions. To find the onset of the response, we measured the activity in a $20 \mathrm{~ms}$ window sliding in $2 \mathrm{~ms}$ steps, starting from $200 \mathrm{~ms}$ before the fixation onset. This activity was compared with the firing rate observed in the $200 \mathrm{~ms}$ before fixation LED onset (Student's $t$ test, $p<0.05$ ). We determined the latency as the time of the first of five consecutive $2 \mathrm{~ms}$ bins in which the activity was significantly higher than that in the $200 \mathrm{~ms}$ before fixation LED onset. The above procedure was similar to the one reported for area V3A (Nakamura and Colby, 2000).

A multilinear regression analysis was used to check whether neural activity was linearly modulated by vergence and version angles. The following equation was used: $A(X, Y)=a_{0}+a_{1} X+a_{2} Y$, where $A$ represents the neural activity in spikes per second; $X$ and $Y$ are the values of vergence and version, respectively; $a_{0}$, the intercept; $a_{1}$ and $a_{2}$, the corresponding regression coefficients. Positive values of $a_{1}$ and $a_{2}$ indicate that a cell increases its activity when the gaze is directed to near and contralateral targets, respectively.

Temporal evolution of the fixation-related discharge. To evaluate the temporal evolution of the modulation by vergence and/or version, we counted, for each neuron, the number of spikes in seven successive 200 $\mathrm{ms}$ bins, two before and five after the beginning of fixation period (Fig. 2). The beginning of the fixation period was assessed separately for each animal by computing, in each trial and for each cell, the time offset of the saccade that brought the monkey's eyes on the fixation LED. The mean saccade offset time with respect to the LED onset was $305.14 \pm 32.21 \mathrm{~ms}$ in monkey A and $245.94 \pm 26.63 \mathrm{~ms}$ in monkey B. To be conservative, we decided to use as a mean time of the beginning of fixation the mean saccade offset plus 2 SDs. This same time point was chosen as the begin- ning of the third bin (i.e., the first bin of fixation; Fig. 2). The other bins (before and after bin 3) were calculated according to bin 3 .

Comparison of spike count data in the $200 \mathrm{~ms}$ bins was performed by applying two-way ANOVA with factor 1 (vergence) with three levels (near, far, intermediate row of the fixation points) and factor 2 (version) with three levels (ipsilateral, contralateral, central row; $p<0.05$ ).

Using the time bin analysis, we found two different types of cells: "transient" cells (Fig. 2A), which increased their firing rate before the saccade onset and stopped firing within the first 400-500 ms of fixation, and "sustained" cells (Fig. 2 B), which started to discharge after the saccade offset and continued for the whole fixation period. With respect to the bins, we defined as transient those cells that were significantly affected by either of the factors (two-way ANOVA, $p<0.05$ ) in bin 3 and/or bin 4 , but not in bins $5-7$, and sustained, those significantly affected in bins 5-7 regardless of whether they were modulated in bins 3-4.

To estimate the time course of the selectivity of neuronal activity in encoding the vergence and/or version signals, we calculated an index (selectivity index, $\eta^{2}$ ) using values obtained from the ANOVA table, and by applying the following formula: $\eta^{2}=\mathrm{SS}_{\text {effect }} / \mathrm{SS}_{\text {total }}$, where $\mathrm{SS}_{\text {effect }}$ is the deviance of the main effect, and $\mathrm{SS}_{\text {total }}$ is the total deviance. We calculated this index for each of the two main effects (i.e., version and vergence) and for every $200 \mathrm{~ms}$ bin of spike data.

Population analysis. For each cell modulated by version and/or vergence, a spike density function (SDF) (Gaussian kernel, half-width 40 $\mathrm{ms}$ ) was calculated for each trial, and then averaged across all the trials referred to a given LED. In each neuron, the maximum discharge frequency in the fixation parts of interest was used to normalize the SDFs. Population SDFs were constructed by averaging the individual SDFs of all the cells (Marzocchi et al., 2008). In all cases, the curves referred to the nine tested positions (or to the three near/far or ipsi/contra rows; Fig. $1 \mathrm{~A}$ ) were statistically compared pairwise with a permutation test with 10,000 iterations comparing the sum of squared errors of the actual and randomly permuted data. The intervals of the curve we compared were different according to the analysis we performed: for cells modulated by version and/or vergence during FIX, the interval was from 50 to $1000 \mathrm{~ms}$ after saccade offset; for the temporal evolution analysis, the interval was from saccade offset until $400 \mathrm{~ms}$ after it for transient cells, and from saccade offset until $1000 \mathrm{~ms}$ after it for sustained cells.

All analyses were performed using custom scripts written in MATLAB (MathWorks).

\section{Histological reconstruction of the recording sites}

At the end of the electrophysiological recordings, a series of electrolytic lesions ( $10 \mu \mathrm{A}$ cathodic pulses for $10 \mathrm{~s}$ ) were performed at the limits of the recorded region. Then animals were anesthetized with ketamine hydrochloride $(15 \mathrm{mg} / \mathrm{kg}$, i.m.) followed by an intravenous lethal injection of sodium thiopental. The animals were perfused through the left cardiac ventricle with the following solutions: $0.9 \%$ sodium chloride, $3.5-4 \%$ paraformaldehyde in $0.1 \mathrm{M}$ phosphate buffer, $\mathrm{pH} 7.4$, and $5 \%$ glycerol in the same buffer. The brains were then removed from the skull, photographed, placed in $10 \%$ buffered glycerol for $3 \mathrm{~d}$ and in $20 \%$ glycerol for $4 \mathrm{~d}$ and cut on a freezing microtome at $60 \mu \mathrm{m}$ in parasagittal plane. One section every five was stained with the Nissl method (thionin, $0.1 \%$ in 0.1 $\mathrm{m}$ acetate buffer, $\mathrm{pH}$ 3.7) for cytoarchitectonic analysis. Procedures to reconstruct microelectrode penetrations and to assign neurons recorded in the anterior bank of the parieto-occipital sulcus to area V6A were as those previously described by our group (Galletti et al., 1996, 1999a,b). Briefly, electrode tracks and the approximate location of each recording site were reconstructed on histological sections of the brain on the basis of several cues, such as electrolytic lesions, the coordinates of penetrations within recording chamber, the kind of cortical areas passed through before reaching the region of interest, the depths of passage points between gray and white matter. All neurons were assigned to the dorsal or ventral sectors of area V6A following the criteria defined by Luppino et al. (2005) and described in detail in a recent work by our group (Gamberini et al., 2011). 

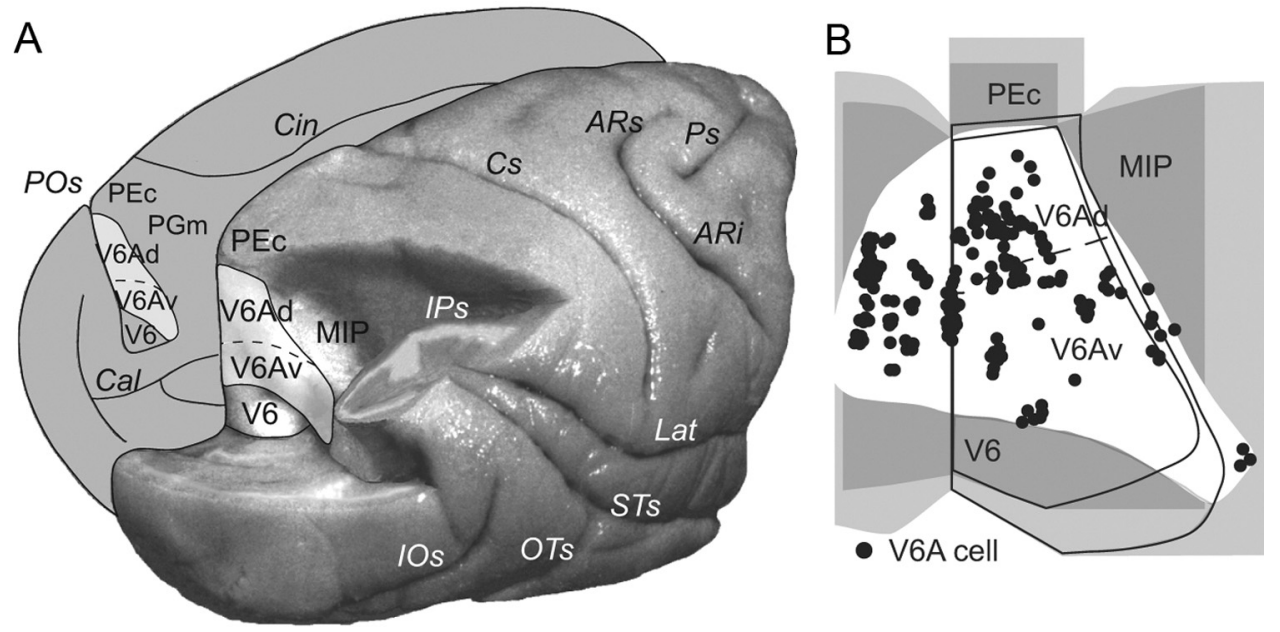

Figure 3. Anatomical reconstruction of the recording sites. A, Posterolateral view of a partially dissected macaque brain (modified from the study by Gamberini et al., 2011). The inferior parietal lobule of the right hemisphere has been cut away at the level of the fundus of the intraparietal sulcus to show the cortex of the medial bank of this sulcus. The occipital lobe of the same hemisphere has been cut away at the level of the fundus of the parieto-occipital and lunate sulci to show the cortex of the anterior bank of the parieto-occipital sulcus. The medial surface of the left hemisphere is drawn to show the location on it of V6Ad and V6Av. B, Summarized flattened map of the superior parietal lobule of the two cases; each dot represents the location in V6A of every neuron tested for eye position in 3D. As evident, the recording site extended all throughout V6A (both V6Ad and V6Av) (Gamberini et al., 2011). P0s, Parieto-occipital sulcus; Cal, calcarine sulcus; Cin, cingulate sulcus; IPs, intraparietal sulcus; IOs, inferior-occipital sulcus; OTs, occipitotemporal sulcus; STs, superior temporal sulcus; Lat, lateral sulcus; Cs, central sulcus; ARs, superior arcuate sulcus; ARi, inferior arcuate sulcus; Ps, principal sulcus; V6, area V6; PEc, area caudal PE; MIP, area middle intraparietal area; PGm, area medial PG.

\section{Table 1. Neurons modulated by vergence and/or version during FIX}

\begin{tabular}{lcc}
\hline & $N$ & $\%$ \\
\hline Vergence only & 38 & 20 \\
Version only & 26 & 14 \\
Vergence + version and no interaction (additive effect) & 32 & 16 \\
Interaction between vergence and version (multiplicative effect) & 47 & 24 \\
None & 49 & 26 \\
Total & 192 & 100 \\
\hline
\end{tabular}

\section{Results}

\section{Recording site}

The anatomical reconstruction of recording sites was performed using the cytoarchitectonic criteria described by Luppino et al. (2005) and the functional criteria detailed by Galletti et al. (1999a) and Gamberini et al. (2011). Figure $3 A$ is a posterolateral view of the partially dissected macaque brain that shows the location of area V6A. Figure 3B shows a superimposition of individual flattened maps of the studied animals, to show the location of cells recorded in area V6A. The maps of the left hemispheres of each case were flipped, so as all recording sites were projected on the maps of the right hemispheres. The map of Figure $3 B$ also shows the average border between the dorsal and ventral part of area V6A (V6Ad and V6Av, respectively). Recorded neurons are located in V6Ad and V6Av.

\section{Main effects of version and vergence on fixation-related activity}

We recorded 192 single cells from area V6A of two monkeys (101 cells from monkey A and 91 cells from monkey B). To investigate the modulating effect of eye version and vergence signals, a twoway ANOVA [factors: version (three levels) and vergence (three levels); $p<0.05$ ] was performed. The incidence of the influence of each factor on neuronal activity is shown in Table 1. Overall, $74 \%$ of cells were modulated by vergence and/or version. Most of them $(40 \%)$ were influenced by both signals while a minority by vergence $(20 \%)$ or version (14\%) alone. Neurons modulated by vergence and version, but not by their interaction (additive ef- fect), were $16 \%$ of the population; neurons modulated by the interaction of version and vergence (multiplicative effect), represented one-quarter of our sample (Table 1). Neurons modulated by version and/or vergence were intermingled in V6A, without any sign of anatomical segregation.

Figure 4 shows two examples of cells modulated by both vergence and version during the fixation period. The neuron of Figure $4 A$ was activated by high vergence angles (near space) and negative version angles (contralateral space). It started firing just before the saccade onset and continued discharging for several hundreds of milliseconds after saccade offset. The neuronal activity was significantly affected by both vergence and version (two-way ANOVA, $p<0.05$ for each factor). The neuron of Figure $4 B$ was more strongly activated for gazing at targets located at intermediate/far positions in the contralateral part of the animal's working space (two-way ANOVA, $p<0.05$ for each factor). Also in this case, the cell response started just before the saccade that caught the target and continued for several hundreds of milliseconds after having got it.

We found that, in $76 \%$ of the tested cells (145 of 192), the discharge rate during FIX was significantly different compared with the last $300 \mathrm{~ms}$ before LED onset (Student's $t$ test between FREE and FIX, $p<0.05$ ). One-half of these cells ( 76 of 145; 53\%) increased their activity during FIX, while a minority (51 of 145 ; $35 \%$ ) was inhibited. In a few cases (18 of $145 ; 12 \%$ ), cells showed a mixed excitation/inhibition pattern of discharge.

Figure 5 shows an example of a cell whose activity was inhibited during FIX. This neuron was modulated by both version and vergence (two-way ANOVA on FIX, $p<0.05$ for each factor). The cell was particularly inhibited when the animal gazed at far or intermediate positions in the contralateral working space. Interestingly, the activity of this neuron started to be inhibited before the onset of the saccade performed by the animal to bring the eyes on the fixation point. In other words, the timing of the modulation of this neuron was similar to that observed in neurons excited by version/vergence changes (Fig. 4).

Figure 6 shows two examples of cells affected by version $(A)$ or vergence $(B)$ only. The neuron shown in Figure $6 A$ was 


\section{Vergence and version influence}

A
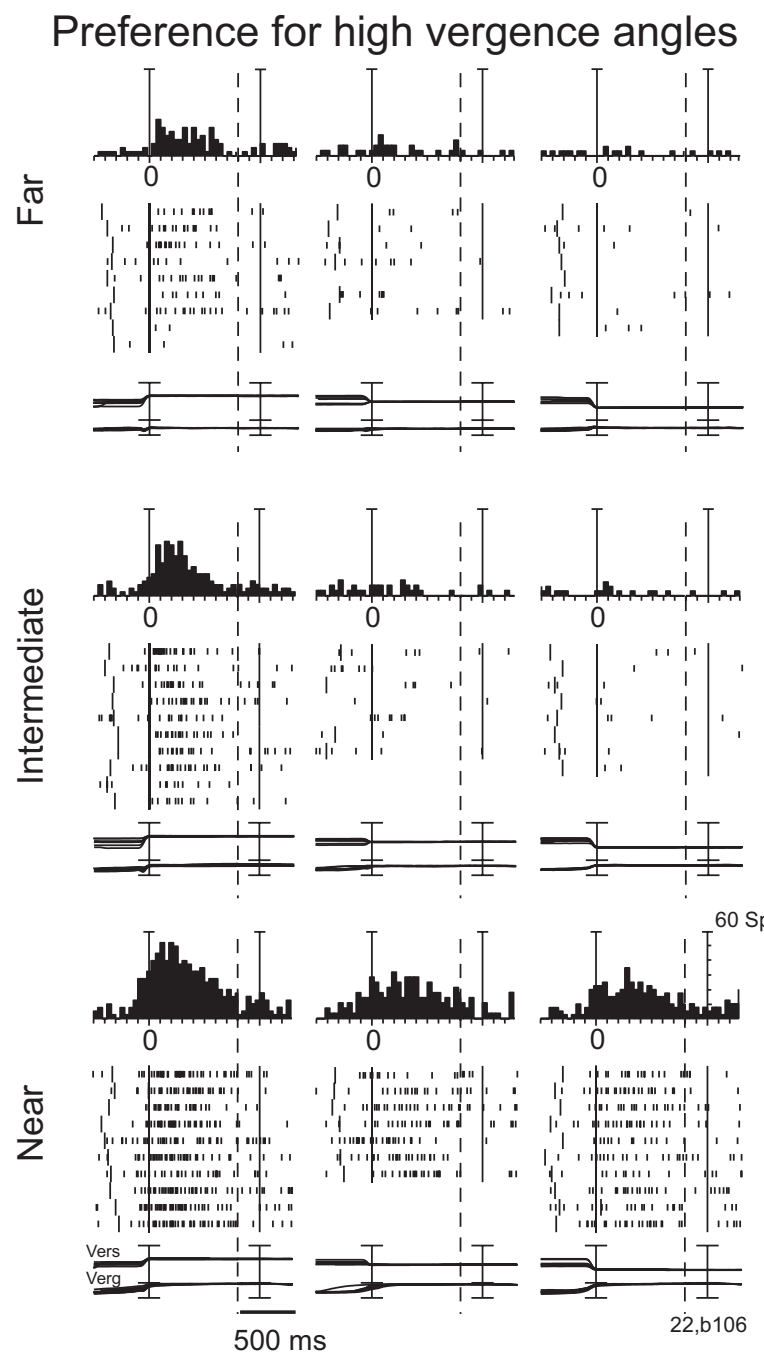

Contra
Center
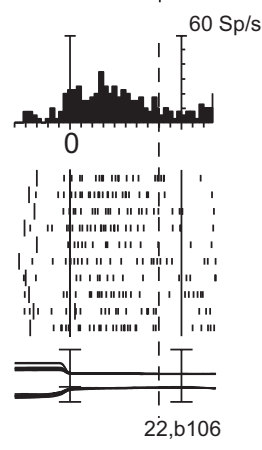

Ipsi
B
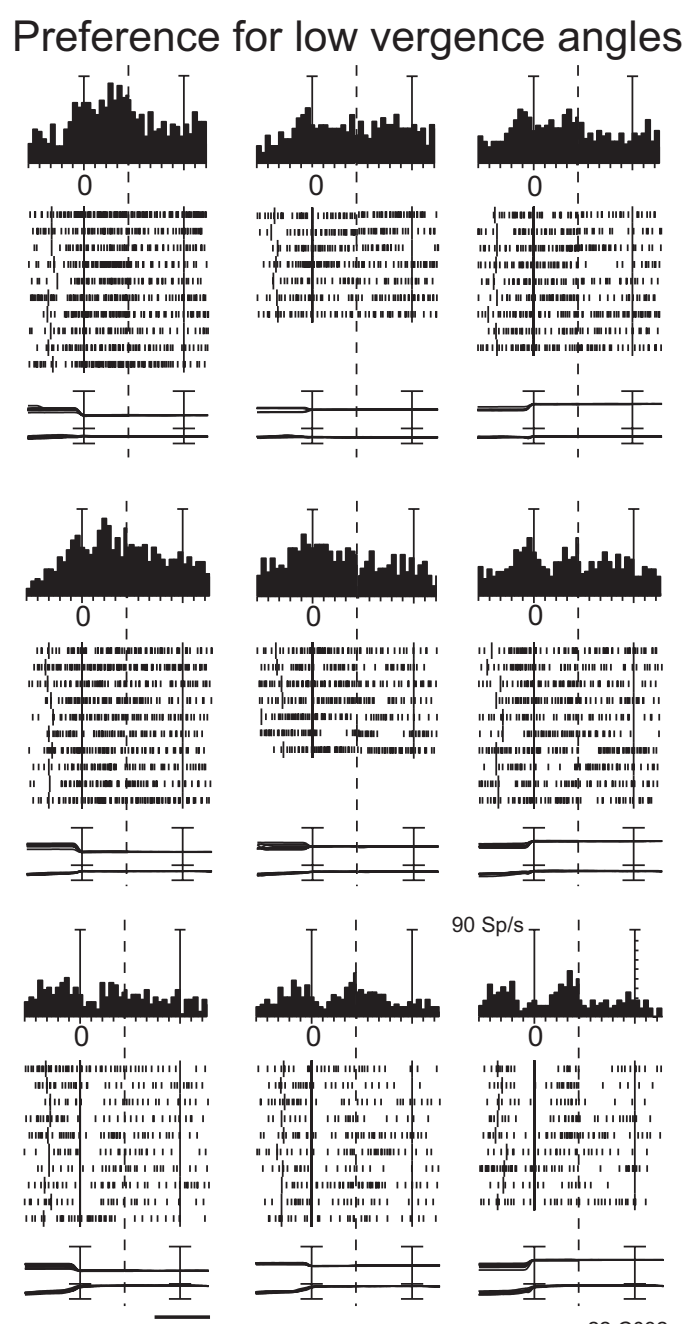

$500 \mathrm{~ms}$

Contra

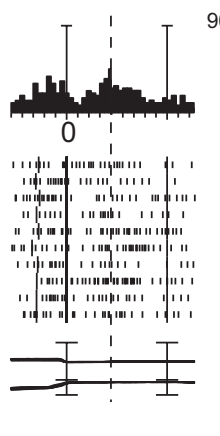

Center
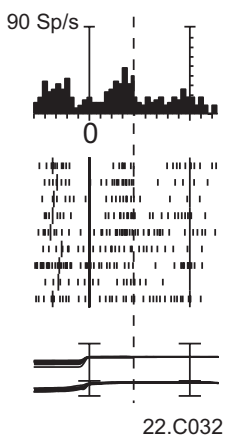

Ipsi

Figure 4. Examples of two V6A neurons modulated by both version and vergence during fixation. $\boldsymbol{A}$, Neuron with highest discharges for fixating near and contralateral targets. $\boldsymbol{B}$, Neuron with highest discharges for far and contralateral targets. For each neuron: discharge to the nine LEDs arranged from near (bottom) to far (top), aligned twice (at the start of the fixation and at the LED change; dashed line, point at which trials were cut because of double alignment). From left to right, the behavioral events are as follows: LED onset, saccade offset (first alignment marker), and LED change (second alignment marker). The cell shown in $\boldsymbol{A}$ had a clear preference for the near-contralateral space (regression equation: Activity $=-9.86+1.52 *$ vergence $+0.36 *$ version); the cell in $\boldsymbol{B}$ for the far-contralateral space (regression equation: Activity $=68.54-2.58 *$ vergence $+0.41 *$ version). Vertical axis scaling for spike histograms: $\boldsymbol{A}, 60 \mathrm{sp} / \mathrm{s} ; \boldsymbol{B}, 90 \mathrm{sp} / \mathrm{s}(10 \mathrm{spikes} / \mathrm{s}$ per division). 0 ther details are as in Figure 2.

activated when the animal gazed at positions located in the contralateral space, but was not significantly affected by the angle of vergence, although near contralateral fixation evoked a weaker discharge than intermediate/far contralateral fixations (two-way ANOVA, $p<0.05$ for version, $p>0.05$ for vergence). On the contrary, the cell in Figure $6 B$ was activated when the animal gazed at near positions but was not significantly affected by the laterality (two-way ANOVA, $p>0.05$ for version, $p<0.05$ for vergence).

The population activity of cells modulated by vergence and/or version is shown in Figure 7. The different plots in Figure 7A show the average SDFs for each target position ranked by the intensity of cell discharge. The "vergence" group contains cells modulated by vergence only or by vergence and version (Fig. $7 \mathrm{~A}$, left). The "version" group contains cells modulated by version only or by version and vergence (Fig. $7 A$, right). In both cases, the activity started to be modulated before the saccade that caught the target, and lasted until the end of fixation. Most of the comparisons between curves relative to different positions were significant (permutation test, $p<0.05$ ). The strengths of the modulating effect of version and vergence were comparable (see the distance between the lines of best and worst positions). Interestingly, both cell populations showed excitation for certain spatial positions and inhibition for others.

Figure $7 B$ shows that, by averaging the activities of all cells modulated by vergence (Fig. $7 B$, left) or version (Fig. $7 B$, right) and ranking them for position in space, the spatial tuning during fixation almost disappeared (particularly for vergence modulations), with no clear preference for a part of space. The same behavior was observed when considering separately the cells 


\section{Inhibition by vergence and version}
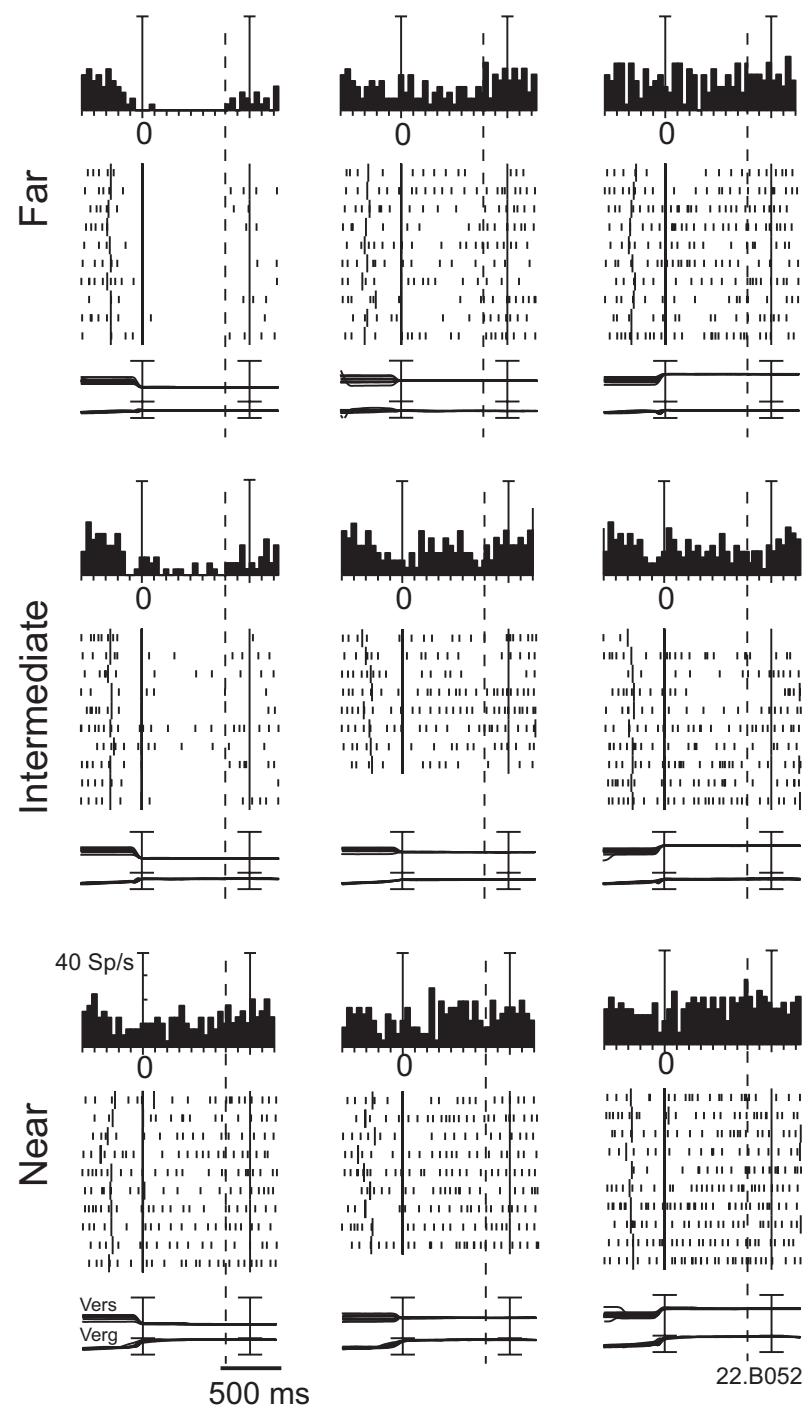

Contra

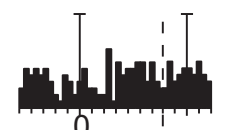

0

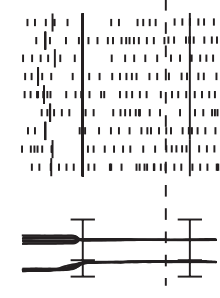

Center
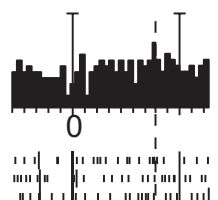

"IIII"

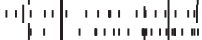

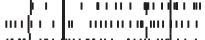

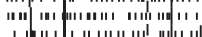

$\mid$
1

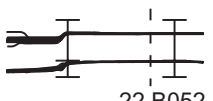

22.'B052

Ipsi

Figure 5. Example of a neuron inhibited when the monkey fixated the intermediate-farcontralateral targets. The regression equation is as follows: Activity $=0.57 *$ vergence 0.28 * version. Vertical axis scaling for histograms: $40 \mathrm{sp} / \mathrm{s}$ (10 spikes/s per division). Other conventions are as in Figure 2.

modulated by version only, by vergence only, or by both (not shown in the figure).

To assess the presence of a linear effect of version and vergence on the activity during FIX, a multilinear regression analysis was applied. A significant linear fit $(p<0.05)$ was found in the vast majority of cells (Table 2): $84 \%$ of neurons were linearly modulated by vergence only or by vergence and version, and $86 \%$ of cells were linearly modulated by version only or by version and vergence. In the cells linearly modulated by vergence, $44 \%$ increased their discharge when the gaze was directed to the near space and $56 \%$ when animals fixated far targets. In the cells modulated by version, $61 \%$ increased their discharge when the gaze was directed to contralateral space and 39\% when animals fixated ipsilateral targets. Statistical comparisons of the percentages of the two categories in each group of cells were not significant ( $\chi^{2}$ test, $p>0.05$ ). In other words, the incidence of cells that increased their activity

during fixation of positions in the near and far space, or in the contralateral and ipsilateral space, was balanced in the entire population. This finding well agreed with the results of the population SDF analysis (Fig. 7B).

\section{Time course of fixation-related activity}

The onset of fixation activity varied among cells and target positions. Figure 8 shows the cumulative frequency distribution of the latencies of the neural responses with respect to the beginning of fixation (fixation onset). Negative values represent responses starting before fixation onset, positive values responses starting after fixation start. As shown in Figure $8, \sim 80 \%$ of V6A cells discharged before the time the earliest proprioceptive signals arrive in somatosensory cortex ( $\sim 60 \mathrm{~ms}$ ) (Xu et al., 2011). This suggests that, in most cases, in V6A the source of oculomotor signals is a corollary discharge. Figure 8 also shows that the majority of cells modulated in FIX $(\sim 60 \%)$ started to respond before fixation onset. Given an average saccade duration of $50 \mathrm{~ms}$, a good number of these cells $(\sim 50 \%)$ would be already responding before the saccade onset. This suggests a strong coupling of perisaccadic and fixation activities, a phenomenon already observed in a recent study from our laboratory (Hadjidimitrakis et al., 2011).

Since $\sim 60 \%$ of V6A neurons are responsive to visual stimulation (Galletti et al., 1996; Gamberini et al., 2011), it could be that the precocious fixation-related discharges we observed are actually visual responses to the fixation-LED appearance. To check this possibility, we compared in single cells the activity during FIX in the preferred position with that recorded when the monkey was sporadically fixating at that same location at the beginning of the trial, before LED onset (Student's $t$ test, $p<0.05$ ). Of the 20 fixation-related neurons in which we had the possibility to perform this analysis, $8(40 \%)$ showed a significant difference before and after the LED appearance. In the remaining 12 cells $(60 \%)$, the discharge in the dark, before LED onset, was not significantly different from that during LED fixation. These results suggest that, in the majority of neurons, the precocious fixation activity was related to oculomotor signals instead of to visual stimulation.

To investigate the timing of activity modulation by vergence/ version during the task, we quantified the neural activity in seven consecutive $200 \mathrm{~ms}$ bins, as detailed in Materials and Methods. In all bins and for all the neurons that were modulated by vergence and/or version during FIX (same populations as in Fig. 7), we performed a two-way ANOVA and then we calculated a selectivity index $\left(\eta^{2}\right)$ (see Materials and Methods) to evaluate the strength of the effects of the independent variables on neuronal activity across time. The $\eta^{2}$ index was calculated for each of the two factors (vergence/version). As shown in Figure 9, the average selectivity for both vergence (solid line) and version (dashed line) developed quickly during the saccade (bin 2), reached a maximum at the beginning of fixation (bin 3-4), and decayed during subsequent fixation intervals (bins 4-7). The selectivities for vergence and version were statistically different in bins 4,5 , and 6 (Student's $t$ test, $p<0.05$ ), with version selectivity decaying more quickly than vergence selectivity.

The neural modulation during fixation showed different time courses in different neurons (see examples in Figs. 4-6). On the basis of the time course of modulation, cells were subdivided in two categories: transient cells, whose discharge rate changed before the saccade onset and returned to FREE level within 400-500 ms (Fig. 2A); these cells were modulated (two-way ANOVA, $p<$ 0.05 ) only in the first two bins of fixation (bins $3-4$ ); and sus- 
A

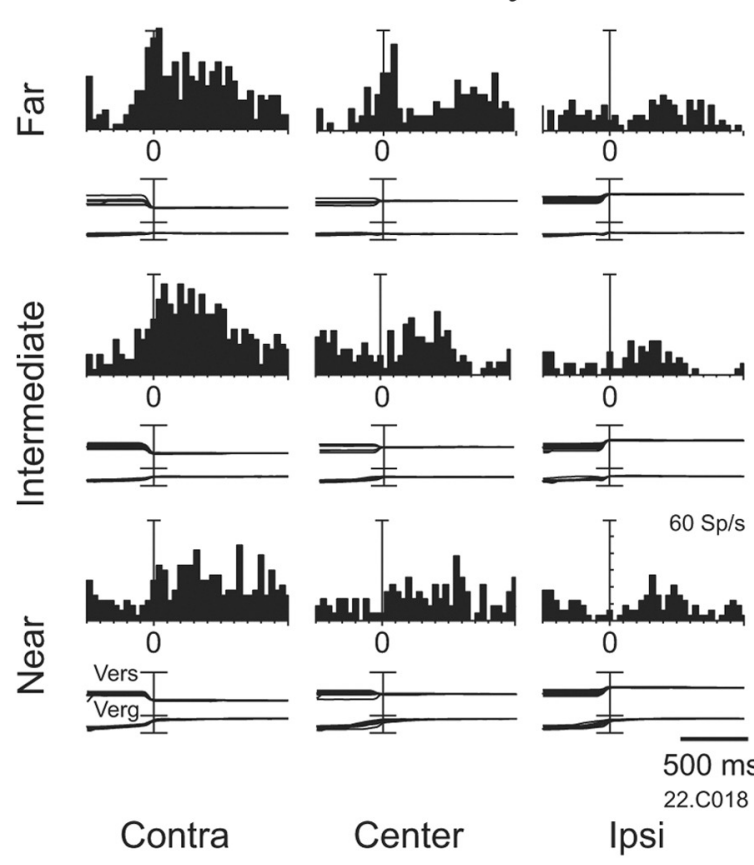

B
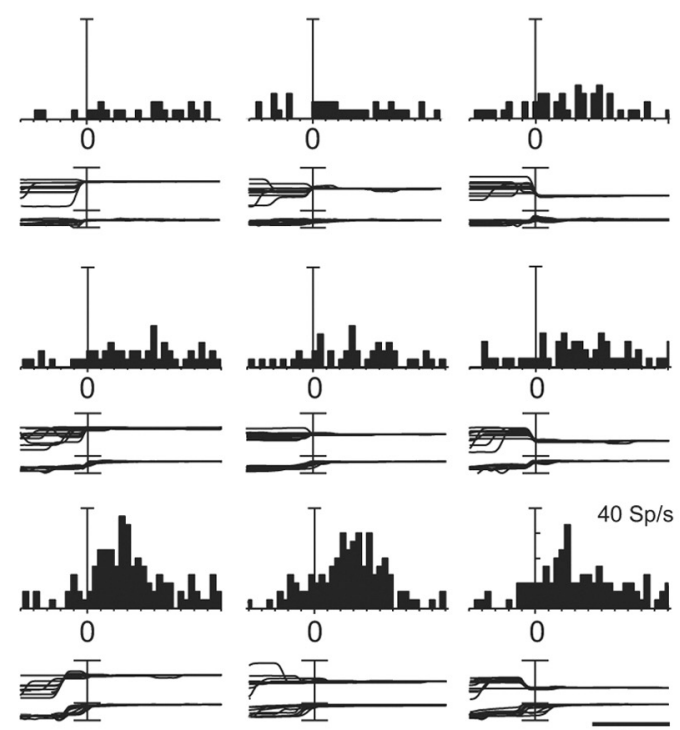

0

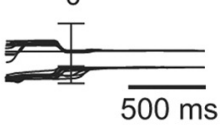

Contra

Center Ipsi

Figure 6. Examples of two neurons modulated by vergence only or by version only. $\boldsymbol{A}$, Example of a neuron modulated only by version. The regression equation is as follows: Activity $=13.21+$ 0.48 * version. Vertical axis scaling for histograms: $60 \mathrm{sp} / \mathrm{s}$ (10 spikes/s per division). $\boldsymbol{B}$, Example of a neuron modulated only by vergence. The regression equation is as follows: Activity $=-4.43$ +0.76 * vergence. Vertical axis scaling for histograms: 40 sp/s (10 spikes/s per division). Other conventions are as in Figure 2.

tained cells, whose response continued beyond 400-500 ms after saccade end (Fig. $2 \mathrm{~B}$ ); these cells were modulated (two-way ANOVA, $p<0.05$ ) in bins $5-7$, and quite often even earlier. Table 3 shows that sustained cells were more numerous than transient cells and that the influence of vergence and version was similar in the two cell groups.

The behavior of cells belonging to each one of the two categories is shown in Figures 10 and 11. Figure 10, $A$ and $B$, illustrates the average SDFs for each target position, ranked by the intensity of discharge in cells with an effect of vergence and version, respectively. In transient cells (Fig. 10 A, B, left), the modulation of activity started just before the saccade, peaked $\sim 250 \mathrm{~ms}$ after saccade offset, and disappeared $\sim 400-500 \mathrm{~ms}$ after the beginning of fixation (permutation test, $p<0.05$ ). In sustained cells (Fig. 10 A, B, right), the tonic activity of fixation peaked $\sim 500 \mathrm{~ms}$ after saccade offset and persisted for at least $1000 \mathrm{~ms}$ after the beginning of fixation. Figure 10, $C$ and $D$, shows the average population activity expressed as SDF of transient and sustained cells, ranked by target positions, in cells modulated by vergence (Fig. 10C) or by version (Fig. 10D). There was no near versus far spatial preference in the cells showing a vergence effect (Fig. $10 C$, permutation test, n.s.), whereas a small but significant preference for the contralateral space was observed in the average activity of cells showing a version effect (Fig. $10 \mathrm{D}$, permutation test, $p<0.05)$.

Figure 11 shows the spatial preference of each of the two groups of cells (transient and sustained). The preferred spatial position of each cell was defined as the gaze position that evoked the highest discharge rate during bin 3 (for transient cells) or bin 5 (for sustained cells). Preferred gaze directions and fixation depths were evenly distributed in transient cells, with a small, nonsignificant preference for the far, contralateral space (Fig. $11 A, B$, left). The sustained cells significantly preferred near and far with respect to intermediate depths, and contralateral space with respect to the central and ipsilateral ones ( $\chi^{2}$ test, $\left.p<0.05\right)$. These data confirm the results of the SDF analysis shown in Figure $10, C$ and $D$.

\section{Discussion}

Present data show that V6A neurons encode eye position in 3D, with a minority of cells encoding only version or vergence, and a majority both of them. While the modulation by version signals in V6A has been known since 1995 (Galletti et al., 1995; Nakamura et al., 1999), the modulating effect of vergence on V6A neurons is a new finding of this report. Together with the previous data, present results suggest that V6A is able to encode the $3 \mathrm{D}$ spatial locations of foveated target. The coexistence in the majority of V6A neurons of both version and vergence modulations demonstrates that the $3 \mathrm{D}$ encoding of space is already present in this early node of the dorsal visual stream.

In our experimental conditions, the activity of the cell during fixation could be the result of extraretinal signals related to gaze in depth or of a visual signal (fixation LED) in turn modulated by the eye position. In both cases, anyway, the activity of the V6A cell is well suited to encode the gazed position in 3D space (Galletti et al., 1995).

Our study reveals that the influence on neural activity of signals related to direction and depth of fixation can be exerted at the onset of fixation (transient response) as well as during fixation (sustained response), thus arguing for the presence of a dynamic representation of eye position in V6A. Our results also demonstrate that version selectivity decays more rapidly than the vergence one (Fig. 9), suggesting a different role for conjugate and disjunctive eye movements in natural head-unrestrained conditions. When we foveate a peripheral object to interact within the peripersonal space, for instance, the fast versionsaccade is usually followed by a (slower) head rotation in the same direction that tends to nullify the conjugate eye rotations 

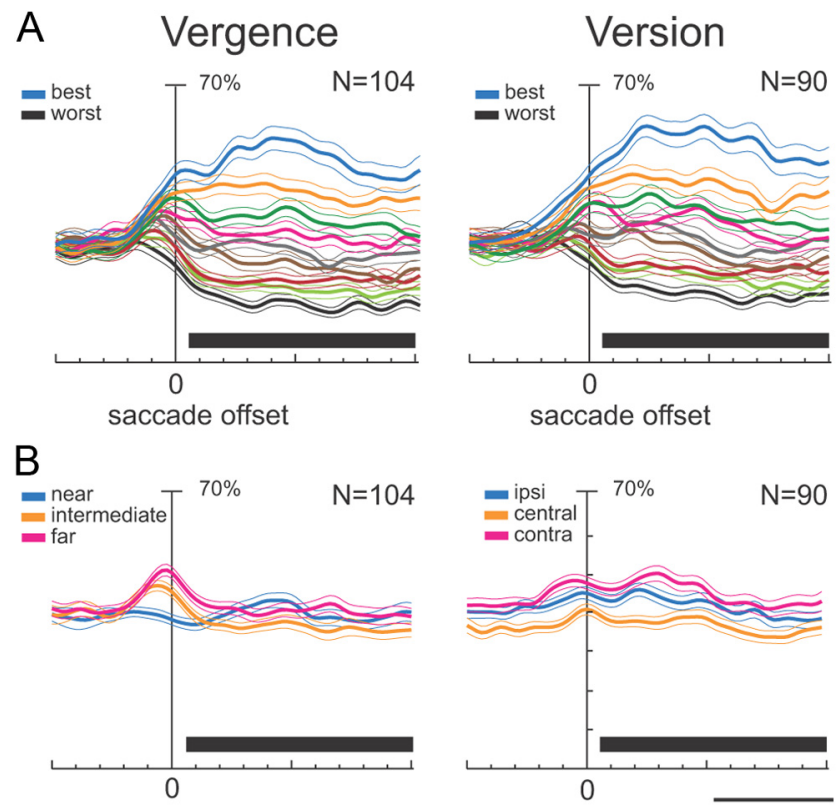

saccade offset

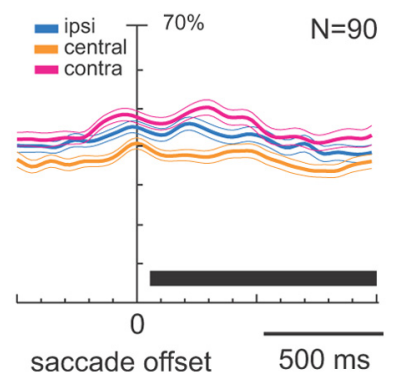

Figure 7. Population activity of V6A neurons modulated during FIX. A, Population average normalized SDFs were constructed by ranking the response of each neuron for each fixation position in descending order according to the intensity of the discharge during FIX. $\boldsymbol{B}$, SDFs were constructed by ranking the response for each tested row of fixation targets. The thick lines indicate average normalized SDF; the light lines indicate variability bands (SEM). Activity is aligned with the offset of the saccade. The black rectangles below each plot indicate the periods where the permutation test was run. Most responses in plots $\boldsymbol{A}$ are statistically different one from the other (permutation test, $p<0.05$ ), indicating that V6A neurons are able to discriminate the different fixation positions both in vergence and in version. In plot $\boldsymbol{B}$ (left), no statistical differences were observed between the curves (permutation test, $p>0.05$ ), in $\boldsymbol{B}$ (right), the central row is statistically different from the other two (permutation test, $p<0.05$ ). The few significant differences in permutation tests in $\boldsymbol{B}$ indicated that there is no clear spatial preference as a whole. Scale on abscissa: $100 \mathrm{~ms}$ /division; vertical scale: $70 \%$ of normalized activity (10\% per division).

Table 2. Results of the multilinear regression analysis

\begin{tabular}{lll}
\hline (Vergence) + (vergence and version) & Near & Far \\
\hline $87 / 104(84 \%)$ & $38 / 87(44 \%)$ & $49 / 87(56 \%)$ \\
(Version) + (version and vergence) & Contra & Ipsi \\
\hline $77 / 90(86 \%)$ & $47 / 77(61 \%)$ & $30 / 77(39 \%)$ \\
\hline
\end{tabular}

and eventually stabilizes the cyclopean central view of the visual target. Thus, long-lasting/prolonged holding of gaze direction is not strictly required in natural behavior. Differently, holding disjunctive (i.e., vergence) eye movements are necessary to maintain the new vergence angle and thus to maintain the object onto the fovea.

Encoding of gaze and ocular movements in depth in V6A has been recently documented by our laboratory (Hadjidimitrakis et al., 2011). We have found that $\sim 50 \%$ of V6A neurons are modulated by gaze direction and depth of fixation when monkeys perform saccades and fixate targets at different locations, in peripersonal as well as in extrapersonal space. We have found responses that in most cases were higher for fixating targets located within the reaching distance, thus supporting the proposed role of V6A in monitoring reach-to-grasp actions (Galletti et al., 2003; Fattori et al., 2009, 2010; Hadjidimitrakis et al., 2011).

In humans, the putative homolog of monkey area V6A is located in the dorsalmost part of parieto-occipital sulcus (POs),

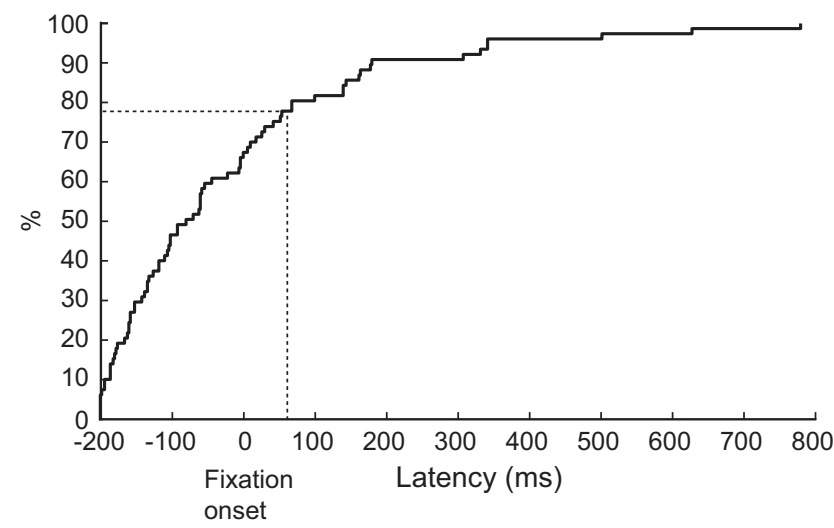

Figure 8. Time course of fixation-related responses. Cumulative frequency distribution plot of the latencies of fixation-related responses in cells with a significantly higher FIX activity compared with FREE. The horizontal axis shows time with respect to the beginning of fixation (saccade offset). The vertical axis indicates the percentage of cells tested $(n=77)$. The vertical dashed line indicates the time $(60 \mathrm{~ms})$ at which the proprioceptive eye position signal influences the activity in area 3a (Xu et al., 2011). The horizontal dashed line indicates that $\sim 80 \%$ of cells are already responding at that time.

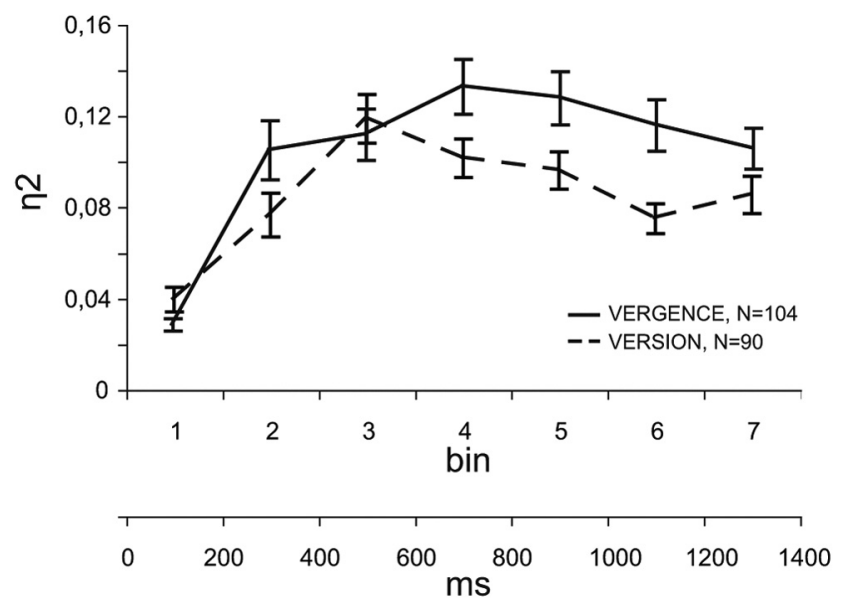

Figure 9. Time course of version and vergence selectivity. Temporal profiles of the magnitude of firing selectivity calculated for the population of neurons modulated by vergence or version during FIX (104 cells for vergence only or vergence and version, solid line; 90 cells for version only or version and vergence, dashed line). Selectivity was calculated as the $\eta^{2}$ index (see Materials and Methods), while variability bars are SEM. Selectivity raised after the beginning of fixation (bin 3) until a maximum and then remained high until the LED change for the entire duration of fixation, even if the decay of version selectivity after fixation onset was more remarkable than the vergence one.

Table 3. Number and incidence (in brackets) of neurons belonging to the two categories defined by the temporal occurrence of the effect

\begin{tabular}{lll}
\hline & Vergence & Version \\
\hline Transient & $28(26 \%)$ & $32(29 \%)$ \\
Sustained & $81(74 \%)$ & $80(71 \%)$ \\
Total & 109 & 112 \\
\hline
\end{tabular}

just anterior to the location of human area V6 (Pitzalis et al., 2006; Cavina-Pratesi et al., 2010). Several studies reported the presence of activations in the dorsalmost part of human POs for changes in the direction of gaze (Law et al., 1998; Williams and Smith, 2010), but to our knowledge only one reported activations in the dorsalmost POs for changes of eye vergence (Quinlan and Culham, 2007). All these findings well agree with present results 

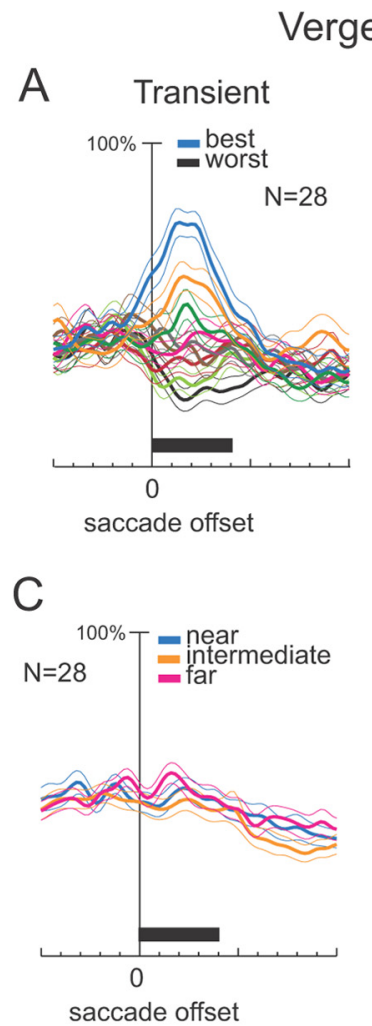
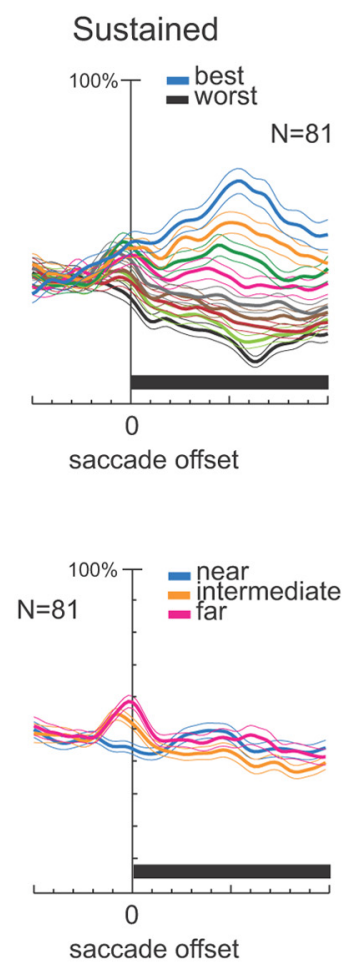

Version
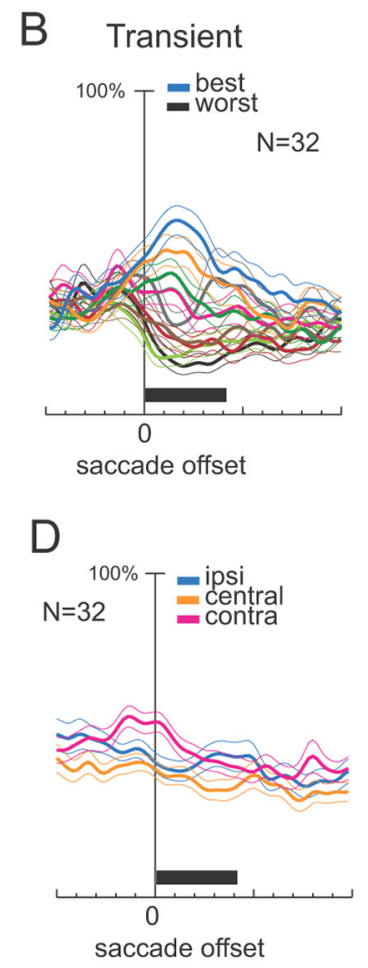
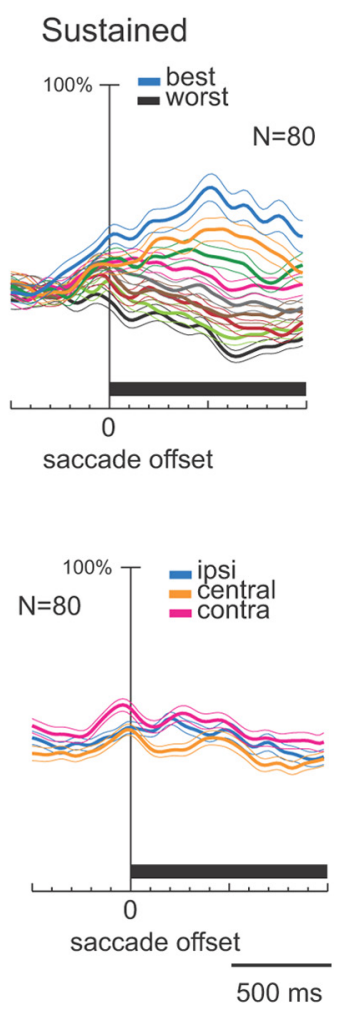

Figure 10. Population activity of V6A neurons modulated in different periods of fixation. $A, B$, Populations average normalized SDFs were constructed by ranking the response of each neuron for each fixation position in descending order according to the intensity of the discharge during the third bin (transient cells, left) or fifth bin (sustained cells, right). C, D, SDFs were constructed by ranking the response for each tested fixation row of targets. Activity is aligned with the offset of the saccade. The black rectangles below each plot indicate the periods where the permutation test was run. Most responses in plots $\boldsymbol{A}$ and $\boldsymbol{B}$ are statistically different one from the other (permutation test, $p<0.05$ ), indicating that V6A neurons are able to discriminate the different fixation positions both in vergence and in version. The few significant differences in permutation tests in the plots in $\boldsymbol{C}$ and $\boldsymbol{D}$ (intermediate vs near and central vs contralateral) indicated that there is no clear spatial preference as a whole. Scale on abscissa: $100 \mathrm{~ms} /$ division; vertical scale: $100 \%$ of normalized activity (10\% per division). Other conventions are as in Figure 7.

and strongly suggest that V6A encodes gaze position in 3D space in both human and nonhuman primates.

\section{Comparison with other areas}

In contrast to the well documented effect of the direction of gaze on the neuronal activity of several brain areas (see Introduction for references), only a few studies have documented an effect of eye vergence signals on single neurons.

Sakata et al. (1980) found in parietal area 7a [mainly area PG of Pandya and Seltzer (1982) and Gregoriou et al. (2006)] results similar to those we obtained here in V6A: the majority of 7a neurons were modulated by both direction of gaze and depth of fixation, while fewer cells were influenced by only one of these factors. Rosenbluth and Allman (2002) demonstrated that a significant number of neurons $(30-50 \%)$ in visual areas V1, V2, V4 were influenced by either gaze direction, depth of fixation, or by their interaction, although the number of cells affected by both signals was not reported. From all these results, it appears that the integration of vergence and version in single neurons does occur at early nodes of the visual stream, such as V6A, or even at earlier stages of the stream (as V1 and/or V2).

Despite the fact that eye position effects have been demonstrated in many cortical areas, the origin of this signal is still unknown. The debate is still open on whether the eye position signal is derived from an efferent copy (corollary discharge) of a motor signal (Von Holst, 1954), or from a proprioceptive signal of eye muscles (Sherrington, 1918). In an elegant experiment, Goldberg (Wang et al., 2007) found a proprioceptive encoding of eye position in area $3 \mathrm{a}$ of the macaque somatosensory cortex, and recently the same group has showed that area 3 a responses followed the eye position signal by $\sim 60 \mathrm{~ms}$ (Xu et al., 2011). As the vast majority of fixation discharges in V6A started before this time point (Fig. 8), our data suggest that their activity mainly reflects a corollary discharge signal. This does not exclude, however, that the later discharge of V6A transient cells and the tonic activity of sustained cells could depend on proprioceptive input.

While our study does not address the question of where the modulatory influence of fixation depth originates, there are several putative sources of vergence information to area V6A. It receives input from the posterior parietal areas LIP and PG (Gamberini et al., 2009), where vergence angle has been reported to have an effect on presaccadic and fixation activities, respectively (Sakata et al., 1980; Genovesio and Ferraina, 2004). Also the area MIP is strongly and reciprocally connected with V6A (Gamberini et al., 2009; Passarelli et al., 2011), and it is known that MIP (also named PRR) hosts neurons with planning activity for reaching modulated by fixation depth (Bhattacharyya et al., 2009). Other possible sources of vergence input are the MST (medial superior temporal) area and the FEFs (frontal eye fields), since both regions contain neurons with vergence-related activity (Inoue et al., 1998; Gamlin and Yoon, 2000; Akao et al., 2005) and send projections to V6A (Gamberini et al., 2009; Passarelli 


\section{Vergence}
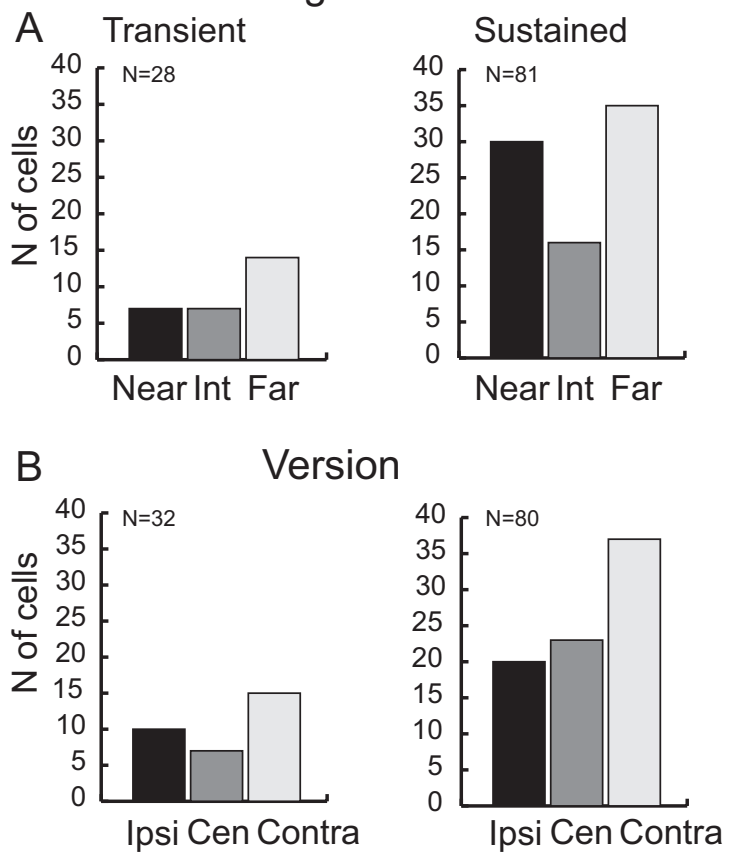

Figure 11. Preferred gaze positions. Frequency histogram showing the preferred position of the transient and sustained neurons. $A$, Target preference for neurons modulated by vergence (vergence only or vergence and version). "Near" refers to the near row of targets ( $18^{\circ}$ of vergence), "Far" to the far row ( $8^{\circ}$ vergence), and "Int" to the intermediate space ( $13^{\circ}$ of vergence). $\boldsymbol{B}$, Target preference for neurons modulated by version (version only or version and vergence). "Ipsi" and "Contra" indicate ipsilateral and contralateral fixation position with respect to the recording hemisphere, respectively. "Cen" refers to the straight ahead of the monkey $\left(0^{\circ}\right.$ of version). Only for cells with a sustained activity is there a significant unequal distribution of spatial preference $\left(\chi^{2}\right.$ test, $\left.p<0.05\right)$.

et al., 2011). Modulations of neural activity by fixation depth have been also found in the VIP (ventral intraparietal) area (Colby et al., 1993) and in visual areas V2 and V4 (Dobbins et al., 1998; Rosenbluth and Allman, 2002), all directly connected with V6A. The two extrastriate areas, in particular, send strong inputs to the ventral part of V6A, which in turn is strongly connected with the dorsal part of V6A (Passarelli et al., 2011), so they are likely candidates to provide depthrelated signals to V6A. Finally, vergence related modulations have been also observed in the primary visual cortex (Trotter et al., 1996) and could be disynaptically transmitted to V6A through area V6 (Galletti et al., 2001).

\section{Transient and sustained encoding of gaze position}

Transient cells are modulated by the direction of gaze and/or by the depth of fixation in a time interval around and shortly after the saccade. They could signal the arrival of the gaze in a new position in $3 \mathrm{D}$ space, as already proposed for posterior parietal areas sensitive to eye position, including area V6A (Nakamura et al., 1999; Genovesio et al., 2007; Raffi et al., 2008). However, since V6A has been recently reported to be activated during covert shifts of attention (Galletti et al., 2010), the spatial modulations observed in transient cells could be related to attentional processes. During gaze shifts to a new spatial location, the spotlight of attention shifts too, together with the gaze, and the timing of attentional shift mimics that of gaze displacement. The attentional effect persists for some hundreds of milliseconds (Bowman et al., 1993; Galletti et al., 2010), like the modulation of activity that we observed in transient cells. Furthermore, the shifts of the spotlight of attention can occur earlier than the change in gaze direction, as observed for the neural discharges occurring before the changes in gaze direction (see examples in Fig. 4).

As far as the sustained cells are concerned, they represent the majority of V6A gaze-modulated neurons. Fixation activity of sustained cells started around the time of saccade and was still present $1000 \mathrm{~ms}$ or more after the saccade offset. In everyday life, when we want to grasp an object, the eyes capture the target well before the hand starts to move (Land et al., 1999; Hayhoe et al., 2003), and when the hand starts moving, the activity of sustained cells could encode the spatial location of gazed object. This signal could be used for the control of the upcoming or ongoing arm reaching movement, a functional role repeatedly proposed for V6A (Fattori et al., 2001, 2005, 2009, 2010; Galletti et al., 2003).

\section{References}

Akao T, Kurkin SA, Fukushima J, Fukushima K (2005) Visual and vergence eye movement-related responses of pursuit neurons in the caudal frontal eye fields to motion-in-depth stimuli. Exp Brain Res 164:92-108.

Andersen RA, Cui H (2009) Intention, action planning, and decision making in parietal-frontal circuits. Neuron 63:568-583.

Andersen RA, Mountcastle VB (1983) The influence of the angle of gaze upon the excitability of the light-sensitive neurons of the posterior parietal cortex. J Neurosci 3:532-548.

Andersen RA, Bracewell RM, Barash S, Gnadt JW, Fogassi L (1990) Eye position effects on visual, memory, and saccade-related activity in areas LIP and 7a of macaque. J Neurosci 10:1176-1196.

Baumann MA, Fluet MC, Scherberger H (2009) Context-specific grasp movement representation in the macaque anterior intraparietal area. J Neurosci 29:6436-6448.

Baylis GC, Baylis LL (2001) Visually misguided reaching in Balint's syndrome. Neuropsychologia 39:865-875.

Bhattacharyya R, Musallam S, Andersen RA (2009) Parietal reach region encodes reach depth using retinal disparity and vergence angle signals. J Neurophysiol 102:805-816.

Bosco A, Breveglieri R, Chinellato E, Galletti C, Fattori P (2010) Reaching activity in the medial posterior parietal cortex of monkeys is modulated by visual feedback. J Neurosci 30:14773-14785.

Bowman EM, Brown VJ, Kertzman C, Schwarz U, Robinson DL (1993) Covert orienting of attention in macaques. I. Effects of behavioral context. J Neurophysiol 70:431-443.

Bremmer F, Distler C, Hoffmann KP (1997) Eye position effects in monkey cortex. II. Pursuit- and fixation-related activity in posterior parietal areas LIP and 7A. J Neurophysiol 77:962-977.

Bremmer F, Schlack A, Duhamel JR, Graf W, Fink GR (2001) Space coding in primate posterior parietal cortex. Neuroimage 14:S46-S51.

Breveglieri R, Dal Bo’ G, Hadjidimitrakis K, Bertozzi F, Bosco A, Galletti C, Fattori P (2011) Eye position signals in monkey medial posterior parietal cortex: combined influence of vergence and version. Abstract presented at Eighth IBRO World Congress of Neuroscience, Florence, Italy, July.

Cavina-Pratesi C, Monaco S, Fattori P, Galletti C, McAdam TD, Quinlan DJ, Goodale MA, Culham JC (2010) Functional magnetic resonance imaging reveals the neural substrates of arm transport and grip formation in reach-to-grasp actions in humans. J Neurosci 30:10306-10323.

Colby CL, Duhamel JR, Goldberg ME (1993) Ventral intraparietal area of the macaque: anatomic location and visual response properties. J Neurophysiol 69:902-914.

Danckert J, Goldberg L, Broderick C (2009) Damage to superior parietal cortex impairs pointing in the sagittal plane. Exp Brain Res 195:183-191.

Dobbins AC, Jeo RM, Fiser J, Allman JM (1998) Distance modulation of neural activity in the visual cortex. Science 281:552-555.

Fattori P, Gamberini M, Kutz DF, Galletti C (2001) “Arm-reaching” neurons in the parietal area V6A of the macaque monkey. Eur J Neurosci 13:2309-2313.

Fattori P, Kutz DF, Breveglieri R, Marzocchi N, Galletti C (2005) Spatial tuning of reaching activity in the medial parieto-occipital cortex (area V6A) of macaque monkey. Eur J Neurosci 22:956-972. 
Fattori P, Breveglieri R, Marzocchi N, Filippini D, Bosco A, Galletti C (2009) Hand orientation during reach-to-grasp movements modulates neuronal activity in the medial posterior parietal area V6A. J Neurosci 29:1928-1936.

Fattori P, Raos V, Breveglieri R, Bosco A, Marzocchi N, Galletti C (2010) The dorsomedial pathway is not just for reaching: grasping neurons in the medial parieto-occipital cortex of the macaque monkey. J Neurosci 30:342-349.

Galletti C, Battaglini PP, Fattori P (1995) Eye position influence on the parieto-occipital area PO (V6) of the macaque monkey. Eur J Neurosci 7:2486-2501.

Galletti C, Fattori P, Battaglini PP, Shipp S, Zeki S (1996) Functional demarcation of a border between areas $\mathrm{V} 6$ and $\mathrm{V} 6 \mathrm{~A}$ in the superior parietal gyrus of the macaque monkey. Eur J Neurosci 8:30-52.

Galletti C, Fattori P, Kutz DF, Gamberini M (1999a) Brain location and visual topography of cortical area V6A in the macaque monkey. Eur J Neurosci 11:575-582.

Galletti C, Fattori P, Gamberini M, Kutz DF (1999b) The cortical visual area V6: brain location and visual topography. Eur J Neurosci 11:3922-3936.

Galletti C, Gamberini M, Kutz DF, Fattori P, Luppino G, Matelli M (2001) The cortical connections of area V6: an occipito-parietal network processing visual information. Eur J Neurosci 13:1572-1588.

Galletti C, Kutz DF, Gamberini M, Breveglieri R, Fattori P (2003) Role of the medial parieto-occipital cortex in the control of reaching and grasping movements. Exp Brain Res 153:158-170.

Galletti C, Breveglieri R, Lappe M, Bosco A, Ciavarro M, Fattori P (2010) Covert shift of attention modulates the ongoing neural activity in a reaching area of the macaque dorsomedial visual stream. PLoS One 5:e15078.

Gamberini M, Passarelli L, Fattori P, Zucchelli M, Bakola S, Luppino G, Galletti C (2009) Cortical connections of the visuomotor parietooccipital area V6Ad of the macaque monkey. J Comp Neurol 513:622-642.

Gamberini M, Galletti C, Bosco A, Breveglieri R, Fattori P (2011) Is the medial posterior-parietal area V6A a single functional area? J Neurosci 31:5145-5157.

Gamlin PD, Yoon K (2000) An area for vergence eye movement in primate frontal cortex. Nature 407:1003-1007.

Genovesio A, Ferraina S (2004) Integration of retinal disparity and fixationdistance related signals toward an egocentric coding of distance in the posterior parietal cortex of primates. J Neurophysiol 91:2670-2684.

Genovesio A, Brunamonti E, Giusti MA, Ferraina S (2007) Postsaccadic activities in the posterior parietal cortex of primates are influenced by both eye movement vectors and eye position. J Neurosci 27:3268-3273.

Gregoriou GG, Borra E, Matelli M, Luppino G (2006) Architectonic organization of the inferior parietal convexity of the macaque monkey. J Comp Neurol 496:422-451.

Hadjidimitrakis K, Breveglieri R, Placenti G, Bosco A, Sabatini SP, Fattori P (2011) Fix your eyes in the space you could reach: neurons in the macaque medial parietal cortex prefer gaze positions in peripersonal space. PLoS One 6:e23335.

Hayhoe MM, Shrivastava A, Mruczek R, Pelz JB (2003) Visual memory and motor planning in a natural task. J Vis 3:49-63.

Holmes G, Horrax G (1919) Disturbances of spatial orientation and visual attention, with loss of stereoscopic vision. Arch Neurol Psychiatry 1:385-407.

Inoue Y, Takemura A, Kawano K, Kitama T, Miles FA (1998) Dependence of short-latency ocular following and associated activity in the medial superior temporal area (MST) on ocular vergence. Exp Brain Res 121:135-144.

Karnath HO, Perenin MT (2005) Cortical control of visually guided reaching: evidence from patients with optic ataxia. Cereb Cortex 15:1561-1569.

Kravitz DJ, Saleem KS, Baker CI, Mishkin M (2011) A new neural framework for visuospatial processing. Nat Rev Neurosci 12:217-230.

Kutz DF, Marzocchi N, Fattori P, Cavalcanti S, Galletti C (2005) Real-time supervisor system based on trinary logic to control experiments with behaving animals and humans. J Neurophysiol 93:3674-3686.

Land M, Mennie N, Rusted J (1999) Eye movements and the roles of vision in activities of daily living: making a cup of tea. Perception 28:1311-1328.
Law I, Svarer C, Rostrup E, Paulson OB (1998) Parieto-occipital cortex activation during self-generated eye movements in the dark. Brain 121:2189-2200.

Luppino G, Hamed SB, Gamberini M, Matelli M, Galletti C (2005) Occipital (V6) and parietal (V6A) areas in the anterior wall of the parieto-occipital sulcus of the macaque: a cytoarchitectonic study. Eur J Neurosci 21:3056-3076.

Marzocchi N, Breveglieri R, Galletti C, Fattori P (2008) Reaching activity in parietal area V6A of macaque: eye influence on arm activity or retinocentric coding of reaching movements? Eur J Neurosci 27:775-789.

Milner AD, Goodale MA (1995) The visual brain in action. Oxford, New York, Tokyo: Oxford UP.

Mountcastle VB (1981) Functional properties of the light-sensitive neurons of the posterior parietal cortex and their regulation by state controls: influence on excitability of interested fixation and the angle of gaze. In: Brain mechanisms of perceptual awareness and purposeful behavior (Pompeiano O, Marsan CA, eds), pp 67-100. New York: Ibro Series, Raven.

Nakamura K, Colby CL (2000) Visual, saccade-related, and cognitive activation of single neurons in monkey extrastriate area V3A. J Neurophysiol 84:677-692.

Nakamura K, Chung HH, Graziano MS, Gross CG (1999) Dynamic representation of eye position in the parieto-occipital sulcus. J Neurophysiol 81:2374-2385.

Pandya DN, Seltzer B (1982) Intrinsic connections and architectonics of posterior parietal cortex in the rhesus monkey. J Comp Neurol 204:196-210.

Passarelli L, Rosa MG, Gamberini M, Bakola S, Burman KJ, Fattori P, Galletti C (2011) Cortical connections of area V6Av in the macaque: a visualinput node to the eye/hand coordination system. J Neurosci 31:1790-1801.

Perenin MT, Vighetto A (1988) Optic ataxia: a specific disruption in visuomotor mechanisms. I. Different aspects of the deficit in reaching for objects. Brain 111:643-674.

Pitzalis S, Galletti C, Huang RS, Patria F, Committeri G, Galati G, Fattori P, Sereno MI (2006) Wide-field retinotopy defines human cortical visual area v6. J Neurosci 26:7962-7973.

Quinlan DJ, Culham JC (2007) fMRI reveals a preference for near viewing in the human parieto-occipital cortex. Neuroimage 36:167-187.

Raffi M, Ballabeni A, Maioli MG, Squatrito S (2008) Neuronal responses in macaque area PEc to saccades and eye position. Neuroscience 156:413-424.

Rosenbluth D, Allman JM (2002) The effect of gaze angle and fixation distance on the response of neurons in V1, V2, and V4. Neuron 33:143-149.

Sakata H, Shibutani H, Kawano K (1980) Spatial properties of visual fixation neurons in posterior parietal association cortex of the monkey. J Neurophysiol 43:1654-1672.

Sherrington GS (1918) Observations on the sensual role of the proprioceptive nerve supply of the extrinsic eye muscles. Brain 41:332-343.

Squatrito S, Maioli MG (1996) Gaze field properties of eye position neurones in areas MST and 7a of the macaque monkey. Vis Neurosci 13:385-398.

Trotter Y, Celebrini S, Stricanne B, Thorpe S, Imbert M (1996) Neural processing of stereopsis as a function of viewing distance in primate visual cortical area V1. J Neurophysiol 76:2872-2885.

Von Holst E (1954) Relations between the central nervous system and the peripheral organs. Br J Anim Behav 2:89-94.

Wang X, Zhang M, Cohen IS, Goldberg ME (2007) The proprioceptive representation of eye position in monkey primary somatosensory cortex. Nat Neurosci 10:640-646.

Williams AL, Smith AT (2010) Representation of eye position in the human parietal cortex. J Neurophysiol 104:2169-2177.

Xu Y, Wang X, Peck C, Goldberg ME (2011) The time course of the tonic oculomotor proprioceptive signal in area $3 \mathrm{a}$ of somatosensory cortex. J Neurophysiol 106:71-77. 